\title{
Anesthesia Protocol for Pediatric Cardiac Surgery Procedures
}

\author{
Leonardo Milella* \\ UOC Head of Anesthesia and Intensive Care TI-CCH Pediatric Hospital "John XXIII", Italy
}

Submission: August 28, 2018; Published: October 04, 2018

*Corresponding author: Leonardo Milella, General Neonatal and Pediatric Anesthesia and Intensive Care Pediatric Hospital "Giovanni XXIII"Viale Amendola 207, 70121-Bari, Italy, Tel: +39-080-559-6624; Fax: +39-080-559-6814, Email: dino.milella@virgilio.it

\section{Introduction}

This anesthetic protocol is applied to a patient population scheduled for routine procedures and / or urgency; special cases and special surgical procedures require dedicated care procedures. Patients undergoing cardiac surgery, with or without the use of extracorporeal circulation (CEC), as per protocol are rarely extubated in the operating room. In recent years there have developed anesthetic techniques of fast track anesthesia which however provide for a restoration of spontaneous breathing nently post-operative period with an extubation in the first four hours after the end of the surgical procedure. The use of sugammadex turns out to be of great help in all those doubtful cases where lack of or inadequate return of spontaneous ventilation is difficult to prove as related to depth of anesthesia and / or neuromuscular blockade, or to causes related to the disease, to the surgical procedures or cardiovascular conditions of the patients.

The use of sugammadex is obliged in all those situations in which a missed intubation or a technical difficulty may lead rapid deterioration in cardiac status in patients with complex desease, premature, malformed babies and heart disease. In this sense, our experience leads us to consider the sugammadex in the same way as a life-saving drug as it is an antidote.

\section{Special Cases}

Syndromic patients, malformed, patients presenting notoriously difficult intubations:

i. Availability in SW of fiberoptic bronchoscope and / or video laryngoscope; flexible $2.8 \mathrm{~mm}, 3.5 \mathrm{~mm}, 5 \mathrm{~mm}$ with tubes $3,3.5,4,5$ preassembled on flexible appropriate gauge.

ii. Not my resolution.

iii. Rapid induction with midazolam, propofol, TPS, sevoflurane, ketamine represented in the port to age, weight, condition, type of surgical procedure.

iv. Larynx topical anesthesia with xylocaine $12 \mathrm{mg} / \mathrm{kg}$ (neonates, infants, up to $30 \mathrm{~kg}$ weight body)

v. Intubation to be sedated. vi. Rocuronium from 0.9 to $1.2 \mathrm{mg} / \mathrm{kg}$ after certain intubation.

\section{Monitoring}

\section{Induction}

i. Heart rate.

ii. $\quad \mathrm{NIBP} \mathrm{SpO}_{2}$.

\section{Post Intubation}

i. Invasive Blood Pressure.

ii. Pediatric Surgery / ENT.

iii. Central venous pressure $\mathrm{SpO}_{2}$.

iv. peripheral temperature.

v. central temperature.

vi. NIRS device two channels.

\section{Additional Monitoring in Particular Cases}

i. Surgical left atrial pressure (post CEC).

ii. Pulmonary artery pressure.

iii. $\mathrm{Scvo}_{2}$

Patients from Hyperflow Shunt Left-Right with or without Pulmonary Hypertension

\section{Patient weight $<5$ kg}

i. $\quad$ Premedication and research venous access

ii. If you do infuse suspend feeding three hours before the procedure

iii. You do not need give premedication to the patient

iv. If there is cannulation of the umbilical vein induce anesthesia from such access and continue anesthesia from such access, which will be removed at the end of intervention

v. If the peripheral venous access is difficult to obtain, induce anesthesia with sevoflurane $3.5-4 \%$ (titrate) 
vi. Not do more than two attempts to cannulate a peripheral vein or external giugular vein

vii. Then find a central venous access.

\section{Anesthesia}

a. Induction: Midazolam 1-2 mg / kg in slow bolus bolus. Rocuronium $1.2 \mathrm{mg} / \mathrm{kg}$.

b. Retention: Except that in particular conditions, maintenance procedures should be started immediately after the arterial cannulation, or immediately in hypertensive patients (eg: aortic coarctation) or in patients in whom we proceed to surgical cannulation of the vessels. TIVA: midazolam 2 to $8 \mathrm{mcg} / \mathrm{kg} / \mathrm{min}$. Alfentanil from 1 to $3 \mathrm{mcg} / \mathrm{kg} / \mathrm{min}$ (do not administer boluses)Rocuronium $1 \mathrm{mg} / \mathrm{kg} / \mathrm{h}$ in continuous infusion. Rocuronium $0.5 \mathrm{mg} / \mathrm{kg}$ before incision; $0.5 \mathrm{mg} / \mathrm{kg}$ before entering the CEC. Possible supplementary dose of morphine $0.1 \mathrm{mg} / \mathrm{kg}$ bolus if the systemic arterial pressure is unstable upward sevoflurane 1-3\%. Suspension of rocuronium immediately after the CEC, or during the sternal closing phase in the patient not in the CEC [1].

\section{Sugammadex}

The administration of sugammadex is provided in all cases of fast track anesthesia for non-complex procedures even if carried out with the aid of CEC and in patients of this weight is not TOF guided due to problems of reliability of the detected value in the premature infant or low weight.

a. Failure Intubation: Sugammadex: $16 \mathrm{mg} / \mathrm{kg}$ in 30 seconds with restoration of spontaneously produce ventilation in 180 seconds. If not resume breathing spontaneously within 180 seconds repeat. Sugammadex: $6 \mathrm{mg} / \mathrm{kg}$ and then it repeats protocol as Special cases.

b. Extubation Routine: Sugammadex: $4 \mathrm{mg} / \mathrm{kg}$ bolus in a minute with restoration of spontaneous ventilation in 180 seconds.

\section{Patient Weight $<10 \mathrm{~kg}>5 \mathrm{~kg}$}

Premedication and research venous access Suspend any fasting from 12 hours and suspend the administration of water from 4 hours. Midazolam 0.09 to $0.1 \mathrm{mg} / \mathrm{kg}+$ droperidrol 1.25 $\mathrm{mg}$ rectally $30 \mathrm{~min}$ - utes before entering the operating room. If the peripheral venous access is difficult to obtain, induce anesthesia with sevoflurane $3.5-4 \%$ (titrate). Not do more than two attempts to cannulate a peripheral vein or external gugula vein. Find a central venous access [2].

\section{Anesthesia}

a. Induction: Midazolam 1-2 $\mathrm{mg} / \mathrm{kg}$ in slow. Bolus Rocuronium $1 \mathrm{mg}$ / kg for induction.

b. Retention: Except that in the maintenance procedures should be started immediately after the arterial cannulation, or immediately in hypertensive patients (eg., coarctation of the aorta) or in patients who proceed to surgical cannulation of the vessels. Midazolam from 2 to $10 \mathrm{mcg} / \mathrm{kg} / \mathrm{min}$. Alfentanil from
1 to $3 \mathrm{mcg} / \mathrm{kg} / \mathrm{min}$ (do not administer boluses). Rocuronium 1 $\mathrm{mg} / \mathrm{kg} / \mathrm{h}$ continuous infusion. Rocuronium $0.3 \mathrm{mg} / \mathrm{kg}$ before incision; $0.3 \mathrm{mg} / \mathrm{kg}$ prior to entry into CEC. Sevoflurane 1-2\%. Suspension of rocuronium immediately after the CEC, or during the closing phase in the patient not in the CEC.

\section{Sugammadex}

The administration of sugammadex is provided in all cases of fast track anesthesia for complex procedures even if not carried out with the aid of CEC and in patients of this weight is not TOF guided due to attendibility problems of the detected value in the patient who weighs less than $10 \mathrm{~kg}$ [3].

a. Failure Intubation: Sugammadex: $16 \mathrm{mg} / \mathrm{kg}$ in 30 seconds with restoration of spontaneously produce ventilation in 180 seconds. If not resume breathing spontaneously within 180 seconds repeat: Sugammadex: $6 \mathrm{mg} / \mathrm{kg}$ and then: It repeats protocol as per Special Cases.

b. Extubation Routine: Sugammadex: $3 \mathrm{mg} / \mathrm{kg}$ bolus in a minute with restoration of spontaneous ventilation in 180 seconds.

\section{Patient Weight $>10 \mathrm{~kg}<30 \mathrm{~kg}$}

Premedication and research venous access suspend any fasting from 12 hours to suspend the administration of water from 4 hours. Midazolam 0.1 to $0.9 \mathrm{mg} / \mathrm{kg}+$ droperidol $2.5 \mathrm{mg}$ rectally 30 minutes before entering the operating room. If the peripheral venous access is difficult to obtain, induce anesthesia with sevoflurane $3.5-4 \%$ (titrate). Not do more than two attempts to cannulate a peripheral vein or external giugular vein. Then find a central venous access [4].

\section{Anesthesia}

a. Induction: Midazolam $0.5 \mathrm{mg} / \mathrm{kg}$ in slow. Bolus Propofol $1 \mathrm{mg} / \mathrm{kg}$ in a minute Rocuronium $1 \mathrm{mg} / \mathrm{kg}$. Rocuronium $0.2 \mathrm{mg} / \mathrm{kg}$ before incision; $0.2 \mathrm{mg} / \mathrm{kg}$ prior to entry into CEC.

b. Retention: Except that in particular the maintenance procedures should be started immediately after the arterial cannulation, or immediately in hypertensive patients (eg., aortic coartation) or in patients in whom we proceed to surgical cannulation of the vessels. TIVA: midazolam 2 to $10 \mathrm{mcg} / \mathrm{kg} / \mathrm{min}$ propofol from 1 to $3 \mathrm{mg} / \mathrm{kg} / \mathrm{h}$ (as an alternative to midazolam) TIVA: alfentanil from 1 to $3 \mathrm{mcg} / \mathrm{kg} /$ Min (do not administer boluses). Rocuronium $1 \mathrm{mg} / \mathrm{kg} / \mathrm{h}$ in continuous infusion. Rocuronium $0.2 \mathrm{mg} / \mathrm{kg}$ before incision; $0.2 \mathrm{mg} / \mathrm{kg}$ prior to entry into CEC. Sevoflurane 1-2\%. Suspension of rocuronium immediately after the $\mathrm{CEC}$, or during the closing phase in the patient not in the CEC [5].

\section{Sugammadex}

The administration of sugammadex is provided in all cases of fast track ane- sthesia for complex procedures even if not carried out with the aid of the CEC. TOF tour with TOF $>2$. TOF not guided with spontaneous breathing in FR $>15$ acts minute and End Tidal PCO2 $<35$ mmHg. 
a. Failure Intubation: Sugammadex: $16 \mathrm{mg} / \mathrm{kg}$ in 30 seconds with restoration of spontaneously produce ventilation in 180 seconds. If not resume breathing spontaneously within 180 secondary to repeat: Sugammadex: $6 \mathrm{mg} / \mathrm{kg}$ and then: It repeats protocol as per Special cases.

b. Extubation Routine: Sugammadex: $3 \mathrm{mg} / \mathrm{kg}$ bolus in a minute with restoration of spontaneous ventilation within 180 seconds.

\section{Patient Weight $>30 \mathrm{~kg}$}

Premedication and research venous access suspend fasting by 12 hours. Suspend administration of water from 24 hours. Temazepam $5 \mathrm{mg}, 1$ tablet per os at 22. Temazepam $5 \mathrm{mg}$, 1 tablet by mouth 45 minutes before entering the operating room.

\section{Anesthesia}

a. Induction: Midazolam $0.2 \mathrm{mg} / \mathrm{kg}$ bolus. Propofol 1-2 $\mathrm{mg} / \mathrm{kg}$ bolus in a minute. Rocuronium $0.9 \mathrm{mg} / \mathrm{kg}$.

b. Retention: The maintenance should be started immediately after the induction: before and during the patient technication maintain dosages to $50 \%$; immediately before skin incision goes to regimen and after the CEC must be reduced by 50\%. TIVA: Midazolam 2 to $10 \mathrm{mcg} / \mathrm{kg} / \mathrm{min}$. Propofol 1 to $3 \mathrm{mg}$ / kg / h (as an alternative to midazolam). TIVA: Alfentanil 1 to 3 $\mathrm{mcg} / \mathrm{kg} / \mathrm{min}$ (do not administer boluses) Rocuronium $0.9 \mathrm{mg} /$ $\mathrm{kg} / \mathrm{h}$ in continuous infusion. Rocuronium $0.2 \mathrm{mg}$ before incision; $0.2 \mathrm{mg}$ before entering the CEC Sevoflurane 1-2\%. Suspension of the administration of Rocuronium immediately after the CEC, or in the process of closing the patient in cases not in CEC [6].

\section{Sugammadex}

The administration of sugammadex is provided in all cases of fast track ane- sthesia for complex procedures even if not carried out with the aid of the CEC. TOF tour with TOF $>2$. TOF not guided with spontaneous breathing in FR> 15 acts minute and End Tidal PCO2 <35 mmHg.

a. Failure Intubation: Sugammadex: $16 \mathrm{mg} / \mathrm{kg}$ in 30 seconds with restoration of spontaneous ventilation within 180 seconds. If not resume breathing spontaneously within 180 secondary to repeat. Sugammadex: $10 \mathrm{mg} / \mathrm{kg}$ then it repeats protocol as per Special cases extubation routine. Sugammadex: $2 \mathrm{mg} / \mathrm{kg}$ bolus in a minute with restoration of spontaneous ventilation within 180 seconds.

\section{Pathology Patients with Type Cyanogen \\ Patient Weight $<5$ kg}

Premedication and research venous access if you do infuse suspend feeding three hours before the procedure you do not need premedication the patient if present cannulation of the umbilical vein induce anesthesia from such access and continue anesthesia from such access, which will be removed at the end of intervention if the peripheral venous access is difficult to obtain, induce anesthesia with sevoflurane 3.5-4\% (titrate) not do more than two attempts to cannulate a peripheral vein or external giugular vein then find a central venous access.

\section{Anesthesia}

a. Induction: If the patient has a natural history of Tetralogy of Fallot (no s/p MBTS) co-administering immediately after venous cannulation $2 \mathrm{mEq} / \mathrm{kg} \mathrm{NaHCO3}$ - and from 5 to 10 $\mathrm{ml} / \mathrm{kg}$ of plasma expander solution. Midazolam $2 \mathrm{mg}$ Midazolam further slow bolus $1 \mathrm{mg} / \mathrm{kg}$. Ketamine 1-2 mg / kg slowly in at least 4 minutes Rocuronium 1-2 mg / kg.

\section{b. Retention}

Except in special maintenance procedures should be initiated immediately after the arterial cannulation, or immediately in patients who proceed to surgical cannulation of the vessels [6]. TIVA: Midazolam 2 to $8 \mathrm{mcg} / \mathrm{kg} / \mathrm{min}$. Ketanemine from 10 to $40 \mathrm{mcg} / \mathrm{kg} / \mathrm{h}$ (non-administered boluses) Rocuronium $1 \mathrm{mg} /$ $\mathrm{kg} / \mathrm{h}$

Rocuronium $0.2 \mathrm{mg}$ before incision; $0.2 \mathrm{mg}$ before entering the CEC. Possible supplementary dose of morphine $0.1 \mathrm{mg} / \mathrm{kg}$ bolus if the arterial pressure is unstable or there is severe desaturation (eg., In the case of no systemi-pulmonary shunt).

\section{Sugammadex}

The administration of sugammadex is provided in all cases of fast track anesthesia for complex procedures even if not carried out with the aid of CEC and in patients of this weight is not guided TOF because of problems of attention's credibility of the detected value in premature babies or low weight.

a. Failure Intubation: Sugammadex: $16 \mathrm{mg} / \mathrm{kg}$ in 30 seconds with restoration of spontaneous ventilation nea within 180 seconds. If not resume breathing spontaneously within 180 secondary to repeat: Sugammadex: $6 \mathrm{mg} / \mathrm{kg}$ and then: It repeats protocol as per special cases.

\section{b. Extubation Routine}

Sugammadex: $4 \mathrm{mg} / \mathrm{kg}$ bolus in a minute with restoration of spontaneous ventilation within 180 seconds.

\section{Patient weight $<10 \mathrm{~kg}>5 \mathrm{~kg}$}

Premedication and research venous access suspend any fasting from 12 hours to suspend the administration of water from 4 hours. Midazolam 0.09 to $0.1 \mathrm{mg} / \mathrm{kg}+$ droperidol $1.25 \mathrm{mg}$ rectally $30 \mathrm{~min}$ - utes before entering the operating room. If the peripheral venous access is difficult to obtain, induce anesthesia with sevoflurane $3.5-4 \%$ (titrate) [7]. Not do more than two attempts to cannulate a peripheral vein or external giugular vein then find a central venous access.

\section{Anesthesia}

a. Induction: If the patient has a natural history of Tetralogy of Fallot (no s/p MBTS) co-administering immediately after venous cannulation $2 \mathrm{mEq} / \mathrm{kg} \mathrm{NaHCO3-}$ and from\% to $10 \mathrm{ml} / \mathrm{kg}$ of plasma expanders. Midazolam $2 \mathrm{mg}$ in slow bolus. 
Midazolam additional $1 \mathrm{mg} / \mathrm{kg}$ bolus. Ketamine 1-2 mg / kg slowly in at least 4 minutes Rocuronium $1-2 \mathrm{mg} / \mathrm{kg}$.

b. Retention: Except in special maintenance procedures should be initiated immediately after the arterial cannulation, or immediately in patients who proceed to surgical cannulation of the vessels. TIVA: midazolam 2 to $10 \mathrm{mcg} / \mathrm{kg} / \mathrm{min}$. Ketamine from 10 to $40 \mathrm{mcg} / \mathrm{kg} / \mathrm{h}$ (non-administered boluses) Rocuronium 1 $\mathrm{mg} / \mathrm{kg} / \mathrm{h}$ in continuous infusion. Rocuronium $0.2 \mathrm{mg} / \mathrm{kg}$ before incision; $0.2 \mathrm{mg} / \mathrm{kg}$ prior to entry into CEC. Morphine $0.1 \mathrm{mg} / \mathrm{kg}$ in repeated boluses if tachycardic Sevoflurane 1-2\%.

\section{Sugammadex}

The administration of sugammadex is provided in all cases of fast track anesthesia for complex procedures even if not carried out with the aid of CEC and in patients of this weight is not TOF guided due to attendi- bility problems of the detected value in the patient who weighs less than $10 \mathrm{~kg}$ [8].

a. Failure Intubation: Sugammadex: $16 \mathrm{mg} / \mathrm{kg}$ in 30 seconds with restoration of spontaneous ventilation nea within 180 seconds. If not resume breathing spontaneously within 180 secondary to repeat: Sugammadex: $6 \mathrm{mg} / \mathrm{kg}$ and then: It repeats protocol as Special cases.

b. Extubation Routine: Sugammadex: $3 \mathrm{mg} / \mathrm{kg}$ bolus in a minute with restoration of spontaneous ventilation within 180 seconds.

\section{Patient weight $>10 \mathrm{~kg}<30 \mathrm{~kg}$}

Premedication and research venous access suspend eventual supply by 12 hours. suspend administration of water from 4 hours. Midazolam 0.2-0.3 mg / kg + droperidol $2.5 \mathrm{mg}$ rectally 30 minutes before entering the operating room if the peripheral venous access is difficult to obtain, induce anesthesia with Sevoflurano3,5-4\% (titate) not do more than two attempts to cannulate a peripheral vein or external giugular vein then find a central venous access

\section{Anesthesia}

a. Induction: Midazolam 5 mg slow bolus. Ketamine 1-2 $\mathrm{mg} / \mathrm{kg}$ slowly in at least 4 minutes Rocuronium $0.9 \mathrm{mg} \mathrm{kg}$ for induction.

b. Retention: Except in the maintenance procedures should be initiated immediately after the arterial cannulation or immediately in patients who proceed to surgical cannulation of the vessels. TIVA: midazolam 2 to $10 \mathrm{mcg} / \mathrm{kg} / \mathrm{min}$. TIVA: Ketanest- from 10 to $40 \mathrm{mcg} / \mathrm{kg} / \mathrm{h}$ (non-administered boluses) Rocuronium $1 \mathrm{mg} / \mathrm{kg} / \mathrm{h}$ in continuous infusion. Rocuronium $0.2 \mathrm{mg} / \mathrm{kg}$ before incision; $0.2 \mathrm{mg} / \mathrm{kg}$ prior to entry into CEC. Morphine $0.1 \mathrm{mg} / \mathrm{kg}$ in repeated boluses if tachycardic $\%$ Sevoflurane 1-2. Keep deep anesthesia until the end of the procedure.

\section{Sugammadex}

Administration of sugammadex is provided in all cases of anesthesia fast track to avoid complex procedures even if carried out with the help of CEC:

i. TOF tour with $\mathrm{TOF}>2$.

ii. TOF not guided with spontaneous breathing in FR> 15 acts minute and End Tidal PCO $2<35 \mathrm{mmHg}$.

a. Failure Intubation: Sugammadex: $16 \mathrm{mg} / \mathrm{kg}$ in 30 seconds with restoration of spontaneous ventilation nea within 180 seconds. If not resume breathing spontaneously within 180 secondary to repeat: Sugammadex: $6 \mathrm{mg} / \mathrm{kg}$ and then: It repeats protocol as per Special cases.

b. Extubation Routine: Sugammadex: $3 \mathrm{mg} / \mathrm{kg}$ bolus in a minute with restoration of spontaneous ventilation within 180 seconds.

\section{Patient Weight $>30 \mathrm{~kg}$}

Premedication and research venous access suspend power by 12 hours suspend administration of water from 24 hours Temazepam $5 \mathrm{mg}, 1$ tablet per os at 22 Temazepam $5 \mathrm{mg}, 1$ tablet orally $45 \mathrm{~min}$ before entering the operating room.

\section{Anesthesia}

a. Induction: Midazolam $0.3 \mathrm{mg} / \mathrm{kg}$ bolus Propofol 1-2 $\mathrm{mg} / \mathrm{kg}$ in slow bolus Rocuronium $0.9 \mathrm{mg} / \mathrm{kg}$ for induction.

b. Retention: The maintenance should be started immediately after the induction: before and during the TECHNIQUES cation maintain dosages to 50\%; immediately before skin incision goes Por- tato in regimen and after the CEC must be reduced by 50\%. TIVA: propofol from 1 to $3 \mathrm{mg} / \mathrm{kg} / \mathrm{h}$. Ketamine from 10 to $30 \mathrm{mcg} / \mathrm{kg} / \mathrm{h}$ (non-administered boluses) Rocuronium $1 \mathrm{mg} / \mathrm{kg} / \mathrm{h}$ in continuous infusion. Rocuronium $1 \mathrm{mg}$ / kg before incision; $1 \mathrm{mg}$ / kg prior to entry into CEC Sevoflurane $1-2 \%$. Keep deep anesthesia until the end of the procedure.

\section{Sugammadex}

Administration of sugammadex is expected in the first four hours post-operative where it has not had a proper restoration of spontaneous breathing in all cases of fast track anesthesia for non-complex procedures even if carried cuted using CEC. TOF tour with TOF $>2$. TOF not guided with spontaneous breathing in FR $>15$ acts minute and End Tidal PCO $2<35$ mmHg.

a. Failure Intubation: Sugammadex: $16 \mathrm{mg} / \mathrm{kg}$ in 30 with return of spontaneous ventilation within 180 seconds. If not resume breathing spontaneously within 180 seconds repeat: Sugammadex: $10 \mathrm{mg} / \mathrm{kg}$. It repeats protocol as per Special cases.

b. Extubation Routine: Sugammadex: $2 \mathrm{mg} / \mathrm{kg}$ bolus in a minute with restoration of spontaneous ventilation within 180 seconds.

\section{Conclusion}

The dosages of rocuronium and sugammadex used in this protocol are being off-label claims and experience the fruit of the author, do not comply with those indicated for product, therefore, MSD, and those who represent it is exempted from liability if 
others want to adopt such assays. MSD and its representatives inform the medical community to use dosages of rocuronium and sugammadex as indicated in the product CPR.

\section{References}

1. Milella L, Da Cruz E, Gajraj RJ, Corno AF (1997) Computerized Anaesthesia and Normothermic perfusion in paediatric cardiac surgery. The Second World Congress of Pediatric Cardiology and Cardiac Surgery Honolulu, Hawaii;May 11-15,1997;

2. Milella L, Mele D (1998) TCI: preliminary experience in paediatric cardiac anaesthesia. Italy.

3. Milella L (1999) TCI in Paediatric Cardiac Anaesthesia. In: Milella L (Eds.), CARACT 99, $\mathrm{V}^{\text {th }}$ Course in Cardiothoracic Anaesthesia, Milan. Italy.

4. Milella L (2000) Advances in Pediatric Cardiovascular Anesthesia. IX $^{\text {th }}$ Congress of Latin American Society of Cardiology and Cardiac Surgery. USA.

5. Milella L, Calabrese G (2000) TCI in Pediatric Cardiac Anesthesia: a better choice for early extubation? IX ${ }^{\text {th }}$ Congress of Latin American Society of Cardiology and Cardiac Surgery. USA.

6. Milella L, Calabrese G, Fiore T (2005) TCI in Paediatric Cardiac Anesthesia: 59 cases. Minerva Anestesiologica.

7. Milella L, Cassano V (2007) Warm Surgery: our experience. Eur J Cardiothorac surg 31(4): 754-755.
8. Milella L (2014) Anaesthesia protocols in paediatric cardiac surgery : the use of sugammadex-Patients and surgical Procedures. p. 31-43.

9. Milella L (2014) Anaesthesia protocols in paediatric diagnostic and interventional cath lab procedures: the use of sugammadex-Patients and Emodinamic Procedures. p. 44-55.

10. Milella L (2015) Anaesthesia protocols in paediatric video thoraco laparoscopic surgical procedures: the use of rocuronium bromide and sugammadex. p. 41-54.

11. Milella L (2015) $69^{\circ}$ th Italian National Anaesthesia Society Congress (SIAARTI): Paediatric Anaesthesia: Paediatric TIVA-TCI: Tips and Pricks. Italy,

12. Milella L (2017) Teaching Project for analgesic and sedation therapeutics in pediatric patient in ICU. Italy.

13. Milella L (2018) Journal of Pediatrics and Neonatal Care: Neonatal and Pediatric General and Cardiac Anesthesia and ICU: wath"s new in 2017/2018? -Bari Pediatric Hospital Experience-Italy. 8(2).

14. Milella L (2018) Anesthesia Control: A Personal Opinion. Curr Trends Biomedical Engineering \& Biosciences 12(1).

15. Bech L, Milella L, Labellarte C (2018) Continuous non-invasive measurement of stroke volume and cardiac output in infants and children: comparison of Impedance Cardiography NICaS ${ }^{\circledR}$ vs Cardio Q® method. Clin Ter 169(3): e110-113.

\begin{tabular}{l} 
Your next submission with Juniper Publishers \\
will reach you the below assets \\
- Quality Editorial service \\
- Swift Peer Review \\
- Reprints availability \\
- E-prints Service \\
- Manuscript Podcast for convenient understanding \\
- Global attainment for your research \\
- Manuscript accessibility in different formats \\
( Pdf, E-pub, Full Text, Audio) \\
- Unceasing customer service \\
Track the below URL for one-step submission \\
https://juniperpublishers.com/online-submission.php \\
\hline
\end{tabular}

